\title{
RAGE controls leukocyte adhesion in preterm and term infants
}

\author{
Kirsten Buschmann, Raphaela Tschada, Marie-Sophie Metzger, Natascha Braach, Navina Kuss, Hannes Hudalla,
} Johannes Poeschl and David Frommhold ${ }^{*}$

\begin{abstract}
Background: Insufficient leukocyte recruitment may be one reason for the high incidence of life-threatening infections in preterm infants. Since the receptor of advanced glycation end products (RAGE) is a known leukocyte adhesion molecule and highly expressed during early development, we asked whether RAGE plays a role for leukocyte recruitment in preterm and term infants.

Methods: Leukocyte adhesion was analyzed in dynamic flow chamber experiments using isolated leukocytes of cord blood from extremely premature (<30 weeks of gestation), moderately premature (30-35 weeks of gestation) and mature neonates ( $>35$ weeks of gestation) and compared to the results of adults. For fluorescent microscopy leukocytes were labeled with rhodamine 6G. In the respective age groups we also measured the plasma concentration of soluble RAGE (SRAGE) by ELISA and Mac-1 and LFA-1 expression on neutrophils by flow cytometry.

Results: The adhesive functions of fetal leukocytes significantly increase with gestational age. In all age groups, leukocyte adhesion was crucially dependent on RAGE. In particular, RAGE was equally effective to mediate leukocyte adhesion when compared to ICAM-1. The plasma levels of SRAGE were high in extremely premature infants and decreased with increasing gestational age. In contrast, expression of $\beta_{2}$-Integrins Mac-1 and LFA-1 which are known ligands for RAGE and ICAM-1 did not change during fetal development.
\end{abstract}

Conclusion: We conclude that RAGE is a crucial leukocyte adhesion molecule in both preterm and term infants.

Keywords: Fetal, Preterm, Neonate, Neutrophils, Leukocyte adhesion, RAGE, Inflammation

\section{Background}

During the past decades advances in neonatal medicine led to strongly improved survival of extremely premature infants [1]. Nonetheless, especially among very immature infants, infection and sepsis are still the leading causes for mortality and morbidity [2-4]. As immaturity of the innate immune system seems to be one of the reasons for this observation, the role of leukocytes has been addressed by numerous studies [2-5]. In particular, fetal leukocyte recruitment has been increasingly examined both in vitro and in vivo [6-8].

The cascade of leukocyte recruitment plays a crucial role in the immune defense during inflammation [9]. Capture of free flowing leukocytes is followed by leukocyte rolling along the endothelial layer, triggering the activation of $\beta_{2^{-}}$

\footnotetext{
* Correspondence: David.Frommhold@med.uni-heidelberg.de Department of Neonatology, University Hospital, 69120 Heidelberg, Germany
}

integrins, i.e. LFA-1 (CD 11a/CD18) and Mac-1 (CD 11b/ CD18), which interact with different endothelial ligands such as ICAM-1 [10,11]. This leads to firm adhesion to the inflamed endothelium and finally to leukocyte transmigration $[9,12]$.

Recently, Nussbaum et al. and Sperandio et al. investigated leukocyte recruitment during fetal development using flow chamber experiments in humans and a new fetal mouse model $[6,8]$. They showed that fetal leukocyte recruitment matures during pregnancy, which may account for the high susceptibility of preterm infants to invasive infections. Consistent with other studies, they also observed that the expression of leukocyte rolling molecules, L- and P-selectin and P-selectin-glycoprotein-ligand 1 and adhesion molecules ICAM-1, Mac-1 and IL-8receptor increase with gestational age [6,8,13-18].

The receptor of advanced glycation end products (RAGE), a strong activator of nuclear factor kB (Nf-kB) 
[19], is highly expressed during fetal development [20,21]. RAGE plays a crucial role in a variety of inflammatory diseases [22-25]. Beside its signaling function, RAGE serves as a multiligand receptor, binding to high-mobility group box 1 protein, protein S100, Mac-1 and others [10,11,26-29]. Interestingly, RAGE was also discovered to mediate leukocyte adhesion via direct binding to Mac-1 [10,11].

Soluble RAGE (sRAGE) is formed by shedding of the receptor's extracellular domain and therefore lacks intracellular signaling. Thus, sRAGE may serve as a decoy receptor that may antagonize functions of full-length RAGE $[22,23]$. Only very few studies investigated sRAGEexpression in extremely premature infants. Similar to inflammatory conditions in adults they showed decreased fetal sRAGE concentrations in the presence of chorioamnionitis [30,31]. The high fetal RAGE expression indicates a pivotal role of RAGE during early development. However, its function for fetal leukocyte recruitment remains unclear.

Therefore, we investigated RAGE-dependent leukocyte adhesion in premature and term infants at different gestational ages.

\section{Methods}

\section{Sample collection and study population}

All included infants were delivered by primary cesarean section. 5-10 ml of umbilical cord blood was collected immediately after delivery. Children with severe fetal malformations, infectious maternal diseases (i.e. chorioamnionitis) and familial immune diseases were excluded. In addition, $10 \mathrm{ml}$ of peripheral venous blood from healthy adult volunteers was drawn by venipuncture. Standard blood collection tubes (S-Monovette, Sarstedt, Nümbrecht, Germany) containing trisodiumcitrate were used for anticoagulation. Based on their gestational age, as estimated by the date of the last menstrual period and by ultrasound measurements, infants were grouped into extremely premature infants (<30 completed weeks of gestation), moderately premature infants (30-35 weeks of gestation), and mature neonates (>35 completed weeks of gestation). Infants older than 35 gestational weeks were considered to be immunologically mature. Informed, written consent was obtained from all adult volunteers and all mothers whose children were included in our study. The study was approved by the local Medical Ethical Committee of the Ruprecht-Karls-Universität (S-047/2008).

\section{Isolation of polymorph-nuclear leukocytes (PMNs)}

As fetal leukocyte and differential white blood counts may vary largely depending on the gestational age, we isolated and quantified PMNs from the umbilical cord of neonates, premature infants or peripheral venous blood of healthy adults. Whole blood was layered onto a density gradient (LSM 1077; PAA Laboratories GmbH, Coelbe, Germany) and centrifuged $\left(1200 \times g, 20 \mathrm{~min}, 4^{\circ} \mathrm{C}\right)$. The resulting erythrocyte-granulocyte pellet was washed twice in Dulbecco's PBS $\left(1 \mathrm{x}\right.$, without $\mathrm{Ca}^{++}$and $\mathrm{Mg}^{++}$; Invitrogen $\mathrm{GmbH}$, Darmstadt, Germany) and erythrocytes were lysed by hypotonic buffer $\left(0.15 \mathrm{M} \mathrm{NH}_{4} \mathrm{Cl}, 0.01 \mathrm{M} \mathrm{NaHCO}_{3}{ }^{-}\right.$, $0.001 \mathrm{M}$ EDTA, in Aqua ad injectabilia for $7 \mathrm{~min}$ in the dark at room temperature). The remaining cells were washed twice, resuspended in $1 \mathrm{ml}$ PBS, and counted in a Neubauer chamber (Bright-Line ${ }^{\oplus}$, Hausser Scientific, Horsham, PA, USA) using Turks solution (Merck, Darmstadt, Germany). The number of PMNs, lymphocytes, erythroid and myeloid precursors was then quantified by May Gruenwald staining (Merck, Darmstadt, Germany) using known cytomorphological parameters $[7,32,33]$. For additional cell differentiation we performed flow cytometry using standard leukocyte clusters defined by forward-side scatter analysis. To identify PMNs during subsequent flow chamber experiments leukocytes were stained with the fluorescent dye Rhodamine 6G ( $\max$ $10 \mathrm{~min}$ ) which does not stain erythroid cells [34,35].

\section{Preparation of murine sRAGE}

Mouse sRAGE was kindly provided by Prof. Peter Nawroth (Dept of Medicine I \& Clinical Chemistry, University Heidelberg). The preparation is summarized in brief. A plasmid with the coding sequence of the mouse extracellular domain of RAGE (1030 bp) was cloned into pET-DEST42 (Invitrogen, Darmstadt, Germany) and transformed into the Escherichia coli strain BL21. Next, isopropyl D-thiogalactopyranoside induced soluble RAGE (sRAGE) protein expression, which was purified using Protino Ni-TED 2000 columns (Macherey-Nagel, Dueren, Germany). Finally, potential endotoxin contamination was removed by affinity chromatography EndoTrap blue 5/1 (Profos AG, Regensburg, Germany).

\section{sRAGE ELISA}

sRAGE concentrations in citrated plasma were measured with a commercially available sandwich enzyme-linked immunosorbent assay (Biovendor, Modrice, Czech Republik) according to the manufacturer's instruction. This assay is known to specifically detect sRAGE in human plasma. Finally the extinction was determined with a Flashscan microplate reader (Analytik Jena AG, Jena, Germany) at $450 \mathrm{~nm}$.

\section{Flow cytometry}

The expression of Mac-1 and LFA-1 was assessed by flow cytometry as described previously [11]. After red blood cell lysis, $10^{5}$ cells were incubated in the dark with $2 \mu \mathrm{g}$ FITC-conjugated anti-LFA-1 or anti-Mac-1 (eBioscience, San Diego, USA) or $2 \mu$ g FITC-conjugated isotype control antibodies (Mouse IgG1, eBioscience, San Diego, USA). 
Mac-1 and LFA-1 expression was assessed on 10.000 cells per mouse within the neutrophil cluster defined by forward-sideward scatter analysis using LSRII with DIVA software package (Becton Dickinson, San Jose, USA). Expression of Mac-1 and LFA-1 was compared to their respective isotype controls.

For differentiation of cells before and after isolation procedures flow cytometry was performed on $10^{5}$ unstained cells using standard neutrophil, monocyte and lymphocyte clusters defined by forward-sideward scatter analysis.

\section{Flow chamber experiments}

Flow chamber experiments were conducted as described $[36,37]$. In brief, rectangular microglass capillaries (VitroCom, Mountain Lakes, USA) were coated with rh P-selectin ( $4 \mu \mathrm{g} / \mathrm{ml}, \mathrm{R} \& \mathrm{D}$ Systems, Wiesbaden, Germany), rh CXCL8/IL-8 (10 $\mu \mathrm{g} / \mathrm{ml}$, Peprotech, London, United Kingdom), and rh ICAM1 ( $4 \mu \mathrm{g} / \mathrm{ml}, \mathrm{R} \& \mathrm{D}$ Systems) or sRAGE $(4 \mu \mathrm{g} / \mathrm{ml}$ or as indicated) and connected via PE tubing to a $2 \mathrm{ml}$ syringe containing freshly isolated neutrophils. Due to the high number of erythroid progenitors in some groups, cell suspension was then incubated with the fluorescent dye Rhodamine 6G $\left(75 \mu \mathrm{l} / 10^{6}\right.$ cells/ml) for leukocyte staining. The number of neutrophils was now set at $2 \times 10^{6}$ cells $/ \mathrm{ml}$ by counting fluorescent cells in a Neubauer chamber by fluorescent microscopy using the FITC channel (BX51 WI, with a saline immersion objective $\times 20 / 0.95$ NA, Olympus Hamburg). The cell suspension was perfused through the flow chamber and neutrophil adhesion was observed by fluorescent microscopy for 10 minutes under constant flow conditions using a high precision perfusion pump (Harvard Instruments, March-Hugstetten, Germany; wall shear stress $0.1 \mathrm{~Pa}$ ). Images were recorded via a CCD camera system (CF8HS; Kappa) on a Panasonic S-VHS recorder. Permanent adherent fluorescent cells were counted as neutrophil adhesion per field of view (FOV) after $10 \mathrm{~min}$.

\section{Statistics}

Sigma Stat 3.5 (Systat Software, Erkrath, Germany) was used for statistical analysis. Clinical and laboratory parameter of patients, leukocyte adhesion, sRAGE concentration and LFA-1 and Mac-1 expression between groups were compared with one-way ANOVA followed by a multiple pairwise comparison test (Dunn's test) or by Wilcoxon rank-sum test, as appropriate. Statistical significance was set at $p<0.05$ or as indicated.

\section{Results and discussion Study population}

76 infants were included in our study from $7 / 2008$ to $5 /$ 2012. The participants consisted of mature infants $(>35$ gestational weeks, $\mathrm{n}=50$ ), moderately premature infants (30-35 gestational weeks, $\mathrm{n}=14$ ) and extremely premature infants $(<30$ gestational weeks, $n=12)$. In addition, we analyzed blood samples of 29 healthy adult volunteers (male 13: female 16; mean age $=27.6 \pm$ 6.8 years). Reasons for prematurity were placental insufficiency, pre-eclampsia, HELLP syndrome, pathologic Doppler flow, and twin pregnancy. Children with underlying infectious diseases of the mother, e.g. suspected chorioamnionitis were excluded. The patient characteristics and laboratory data are shown in Table 1.

Since children were included consecutively, the gender distribution among the experimental groups shows some variation. As expected, premature infants had a significantly lower birth weight than mature neonates. In addition, white blood-cell count and PMN count in whole blood were significantly lower in premature than in mature infants, an observation that has also been described earlier [6]. Notably, levels of C-reactive protein did not vary between investigated groups. Prenatal steroids (betamethasone) were administered to the majority of mothers of preterm infants. Although steroids are discussed to alter neutrophil function, recently Nussbaum et al. were able to exclude an impact of betamethasone on leukocyte adhesion using the same setting of flow chamber experiments as we did in our study [6]. Therefore, we argue that prenatal steroid administration should not influence leukocyte adhesion in our study.

\section{Age dependent characteristics of PMN isolates}

Since we aimed to specifically investigate adhesion behavior of neutrophils, we tested different PMN isolation procedures and evaluated the resulting purity of the cell suspension. As standard PMN isolation methods using dextrose density gradient centrifugation failed in newborns, we performed an inverse separation with LSM 1077, which primarily isolates lymphocytes. After May-Gruenwald staining of the resulting cell suspension we counted about 90\% PMN in mature newborns compared to 92\% PMN in adults (Figure 1, see also Additional file 1: Figure S1).

These results were confirmed by flow cytometric counts of cell populations using standard gates defined by forward-side scatter analysis: after isolation PMNs increased to $93 \%$ (<1\% monocytes and 7\% lymphocytes or others) in adults and to $88 \%(<1 \%$ monocytes and $12 \%$ lymphocytes or others) in term infants (Additional file 1: Figure S2 and Figure S3). However, after the described PMN isolation procedure we found only $60 \%$ PMNs in moderately premature infants and only $40 \%$ PMNs in extremely premature infants (Figure 1). According to differential staining, the remaining cells were mostly erythroid progenitor cells $(30 \%$ and $50 \%$, respectively) and, less prominent, lymphocytes and myeloid precursors, summed up as others (10\%) at these gestational ages (Figure 1). In contrast, erythroid progenitor cells, lymphocytes and myeloid precursors were 
Table 1 Patient characteristics and laboratory values of umbilical cord blood

\begin{tabular}{|c|c|c|c|c|}
\hline Data & $\begin{array}{l}\text { Extremely premature } \\
\text { ( }<30 \text { weeks) }\end{array}$ & $\begin{array}{l}\text { Moderately premature } \\
\text { (30-35 weeks) }\end{array}$ & $\begin{array}{l}\text { Mature neonates } \\
\text { (>35 weeks) }\end{array}$ & $\begin{array}{l}\mathrm{p} \text { value } \\
\text { (ANOVA) }\end{array}$ \\
\hline Number & $n=12$ & $n=14$ & $n=50$ & \\
\hline \multicolumn{5}{|l|}{ Clinical } \\
\hline GA (weeks) & $284 / 7 \pm 14 / 7$ & $331 / 7 \pm 11 / 7$ & $373 / 7 \pm 12 / 7$ & na \\
\hline Birth weight (g) & $1130 \pm 260^{* \#}$ & $1930 \pm 570^{*}$ & $3040 \pm 520$ & $<0.001$ \\
\hline Female/male & $4 / 8$ & $6 / 8$ & $23 / 27$ & na \\
\hline APGAR $5^{\prime}$ & $8 \pm 1$ & $9 \pm 1$ & $9 \pm 1$ & ns \\
\hline $10^{\prime}$ & $8 \pm 1$ & $9 \pm 1$ & $9 \pm 1$ & ns \\
\hline \multicolumn{5}{|l|}{ Laboratory } \\
\hline Arterial pH & $7.31 \pm 0.07$ & $7.30 \pm 0.04$ & $7.28 \pm 0.05$ & ns \\
\hline $\operatorname{CrP}(\mathrm{mg} / \mathrm{dl})$ & $<0.05$ & $<0.05$ & $<0.05$ & na \\
\hline WBC/nl & $9.3 \pm 3.6^{*}$ & $12.3 \pm 3.9$ & $14.5 \pm 7.9$ & $<0.05$ \\
\hline PMN (\%) & $25.4 \pm 12.8^{*}$ & $32.4 \pm 9.5^{*}$ & $45.5 \pm 14.2$ & $<0.001$ \\
\hline Hct (\%) & $0.45 \pm 0.05$ & $0.50 \pm 0.04$ & $0.48 \pm 0.06$ & ns \\
\hline
\end{tabular}

Data are given as mean \pm SEM if applicable. GA, gestational age; APGAR score; WBC, White blood cell count; Hct, haematocrit; CrP, C-reactive protein; na, not applicable; ns, not significant. The asterisk $\left(^{*}\right)$ indicates significant differences vs. mature neonates and the pound key $\left(^{\#}\right)$ vs moderately premature infants as given by the $P$ value (ANOVA).

hardly found in term infants and adults after isolation (about $10 \%$ and less, Figure 1).

These results are in line with previous studies, demonstrating that the number of circulating erythroid progenitor cells is particularly high in premature infants and that they are difficult to separate from leukocytes due to physical similarities [38-40]. Although these cells have been shown to induce immunosuppression in neonates they should not alter leukocyte adhesion in our flow chamber experiments since they need the whole organism for interaction [38-40]. To answer the question whether erythroid progenitor cells might directly mimic neutrophil behavior during flow chamber experiments, it is important to mention that they only express PSGL-1, but not IL-8 receptor, Mac-1 nor LFA-1 which are crucial adhesion molecules in this setting $[9,12,41,42]$. Thus, it is unlikely that erythroid progenitor cells adhere to flow chambers coated with Pselectin, IL-8 and ICAM-1/RAGE.

However, to exclude varying neutrophil count in cell isolates of different age groups and misinterpretation of adherent cells, all cell isolates were further treated with the fluorescent dye Rhodamine 6G which predominantly

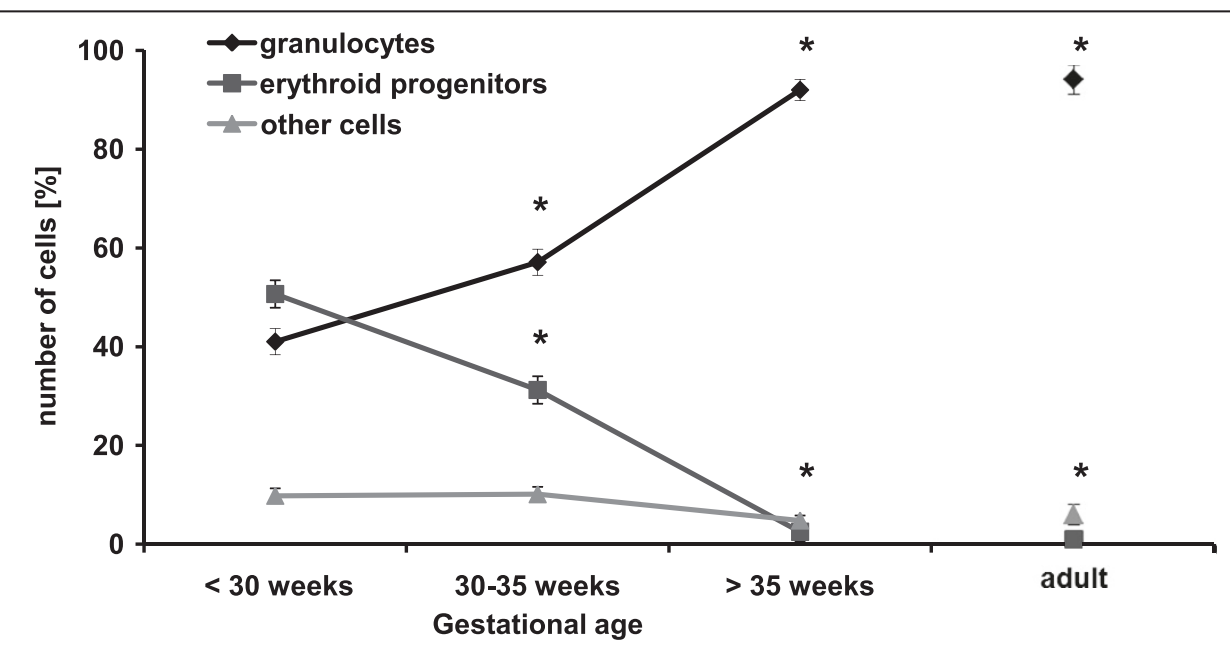

Figure 1 Gestational age dependent distribution of blood cells after PMN isolation procedure. Granulocytes, erythroid progenitors and other cells (lymphocytes and myeloid precursors) from extremely, moderately premature and mature infants as well as adults were counted using differential May Gruenwald staining (mean \pm SEM). Significant differences to extremely premature infants ( $<30$ weeks of gestation) are indicated by asterisks ( $p<0.05$ ). 

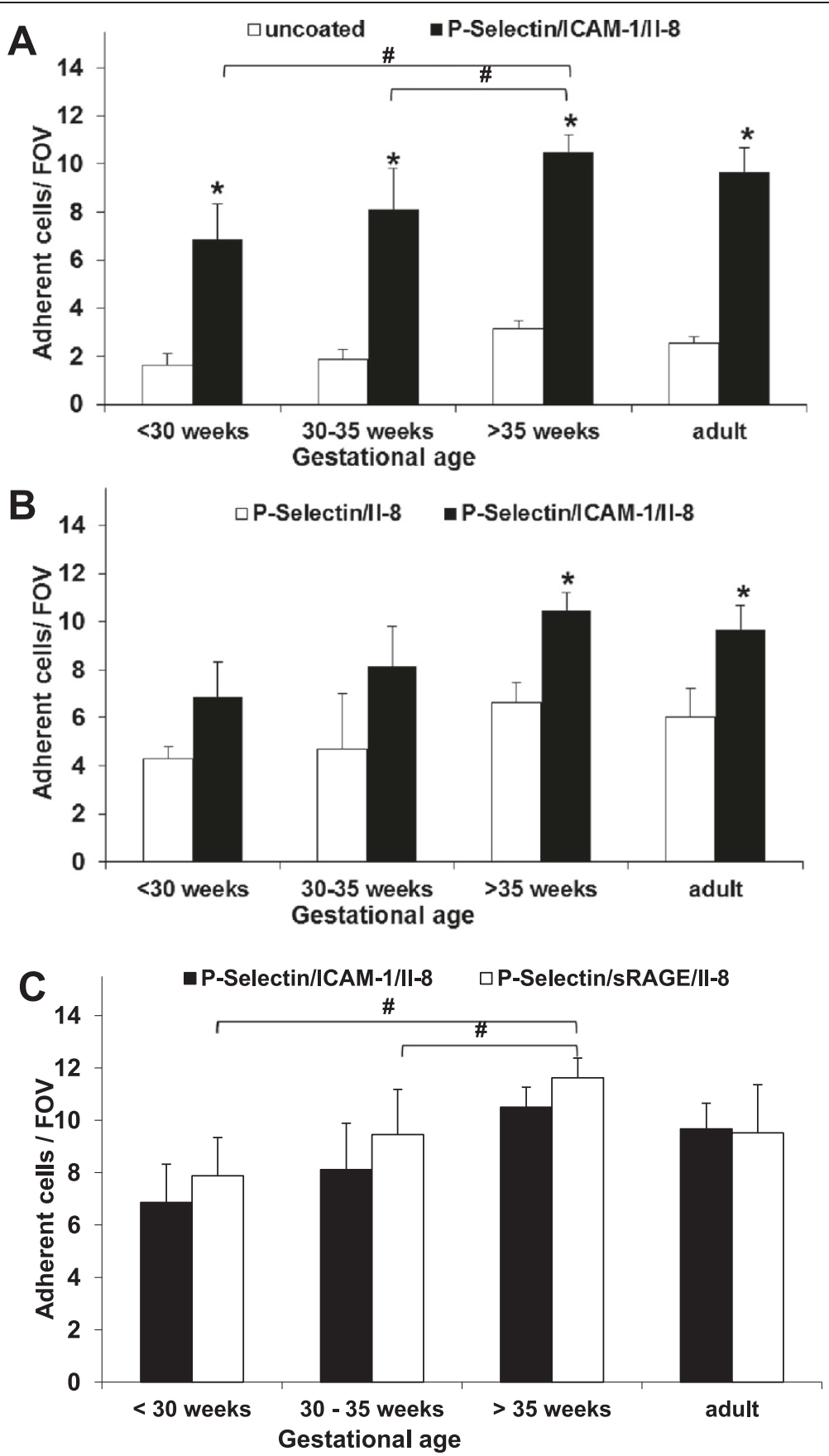

Figure 2 RAGE- and ICAM-1-dependent fetal neutrophil adhesion. Neutrophil adhesion of preterm and term infants and adults was analyzed in dynamic microflow chamber experiments (A) Neutrophil adhesion upon P-selectin, IL-8 and ICAM-1 was compared between the various age groups and to respective uncoated controls. (B) Neutrophil adhesion is shown for P-selectin and IL-8 coated flow chambers with and without ICAM-1. (C) ICAM-1-and SRAGE-dependent neutrophil adhesion in combination with P-selectin and IL-8-coating. Results are presented as mean + SEM from at least 5 separate individuals/experiments per group. Significant differences $(p<0.05)$ to uncoated or P-selectin and IL-8 coated flow chambers are indicated by asterisks and by the pound key (as indicated).

stains leukocytes, while erythroid cells remain unstained [34,35]. Using fluorescent microscopy we were now able to set the number of neutrophils at $2 \times 10^{6} / 2 \mathrm{ml}$ suspension in all age groups and to specifically analyze neutrophil adhesion in flow chamber experiments.
In-vitro neutrophil adhesion in preterm and term infants In order to investigate the role of RAGE for fetal leukocyte recruitment, we measured adhesion of neutrophils of adults, term and premature infants in dynamic microflow chambers experiments (see also representative 
screenshot in Additional file 1: Figure S4). Different coating of flow chambers allowed a functional analysis of the used or omitted molecules. As reported previously $[37,43]$, we first used a combination of P-selectin, IL- 8 and ICAM-1, which triggers significant adhesion of adult neutrophils when compared to uncoated controls (Figure 2A). This molecular coating also led to a relevant adhesion of neutrophils of neonates or premature infants compared to their respective controls. However, the number of neutrophils that adhered on P-selectin, IL-8 and ICAM-1 gradually and significantly increased with gestational age from only $6.8 \pm 1.4$ /FOV in very premature infants to $8.1 \pm 1.7 / \mathrm{FOV}$ in moderately premature infants and $10.5 \pm 0,8 / \mathrm{FOV}$ in term neonates (Figure 2A). Very recently, Nussbaum et al. similarly reported a gestational age-dependent increase of leukocyte adhesion in a dynamic flow chamber approach [6]. They also found comparable leukocyte adhesion when P-selectin is replaced by E-selectin [6].

To investigate the role of the integrins for leukocyte adhesion preterm infants and neonates, we compared leukocyte adhesion in flow chambers only coated with P-selectin and IL-8 with those with additional ICAM-1 coating. We found reduced leukocyte adhesion in ICAM-1 lacking flow chambers in all age groups, although the level of significance was not reached in premature infants (Figure 2B). This might be caused by the relatively small number of samples as well as the generally low level of adhesion in the premature groups. Nevertheless, our results point towards an important role of the interaction of $\beta_{2}$-integrins with their ligands and suggest that the combination of all three adhesion molecules used is crucial for effective in vitro leukocyte adhesion not only in adults [11], but also in preterm and term infants.

To determine the role of RAGE for leukocyte adhesion in preterm infants and neonates we replaced the $\beta_{2}$-integrin ligand ICAM-1 by sRAGE and in a first step performed dose-finding-experiments. In previous experiments, sRAGE coating with $4 \mu \mathrm{g} / \mathrm{ml}$ was successfully used to induce adult leukocyte adhesion [11]. sRAGE coating concentrations ranging from $0.5-20 \mu \mathrm{g} / \mathrm{ml}$ were tested in neonates in combination with P-selectin and IL-8 and revealed optimal leukocyte adhesion at $4 \mu \mathrm{g} / \mathrm{ml}$ sRAGE, too (Additional file 1: Figure S5). Since this coating concentration was exactly the same as for ICAM-1 it was used in all consecutive experiments. Notably, sRAGE concentrations higher than $10 \mu \mathrm{g} / \mathrm{ml}$ resulted in a decrease in leukocyte adhesion which might be due to inhibiting effects of free circulating sRAGE in the flow chamber as a result of sRAGE coating overdose [44].

Next, we found that sRAGE mediates leukocyte adhesion in both adults and during investigated stages of fetal life (Figure 2C). Similar to ICAM-1-coating, RAGEcoating in combination with P-selectin and IL-8 induced significant adhesion of neutrophils from infants and adults when compared to uncoated controls (not depicted). As observed for ICAM-1-dependent neutrophil adhesion, we also found that the number of adherent neutrophils significantly increased with gestational age, i.e. $7.8 \pm 1.4 / \mathrm{FOV}$ in very premature infants, $9.4 \pm 1.7 / \mathrm{FOV}$ in moderately premature infants and $11.6 \pm 0.8 / \mathrm{FOV}$ in term neonates (Figure 2C, see also Additional file 1: Figure S4).

As demonstrated and discussed earlier in this study, the preparation technique (separation or staining) cannot explain these observations. In order to rule out unspecific

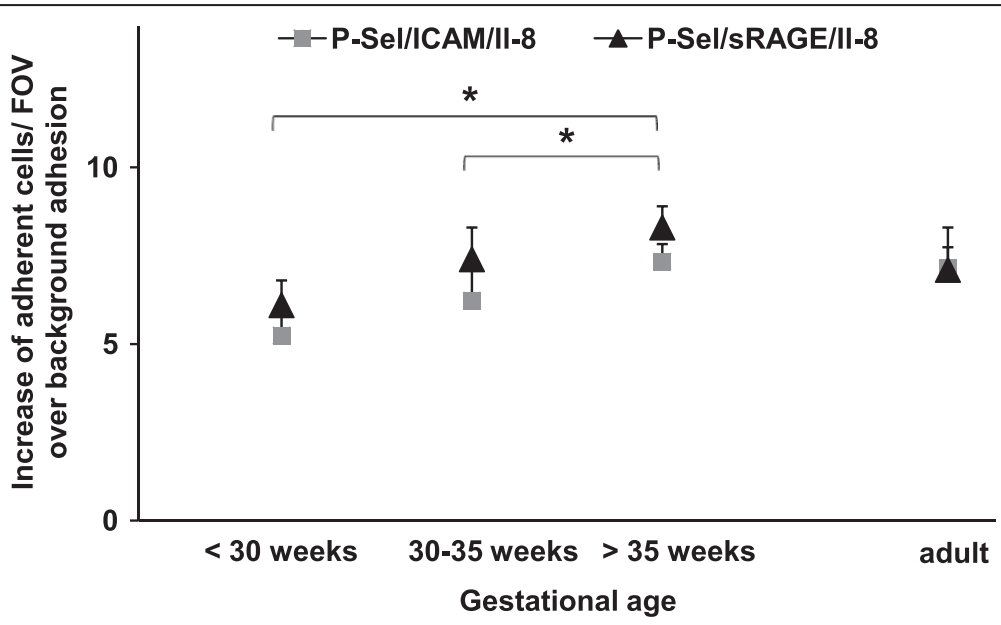

Figure 3 Effective RAGE- and ICAM-1-dependent fetal neutrophil adhesion. Neutrophil adhesion of preterm and term infants and adults was analyzed in dynamic microflow chamber experiments. The difference of neutrophil adhesion between uncoated controls and coating with P-selectin, IL-8 and RAGE or ICAM-1 is displayed as increase of adherent cells/FOV over background for the respective age groups. Results are presented as mean + SEM from at least 5 separate individuals/experiments per group. Significant differences $(p<0.05)$ are indicated by asterisks. 


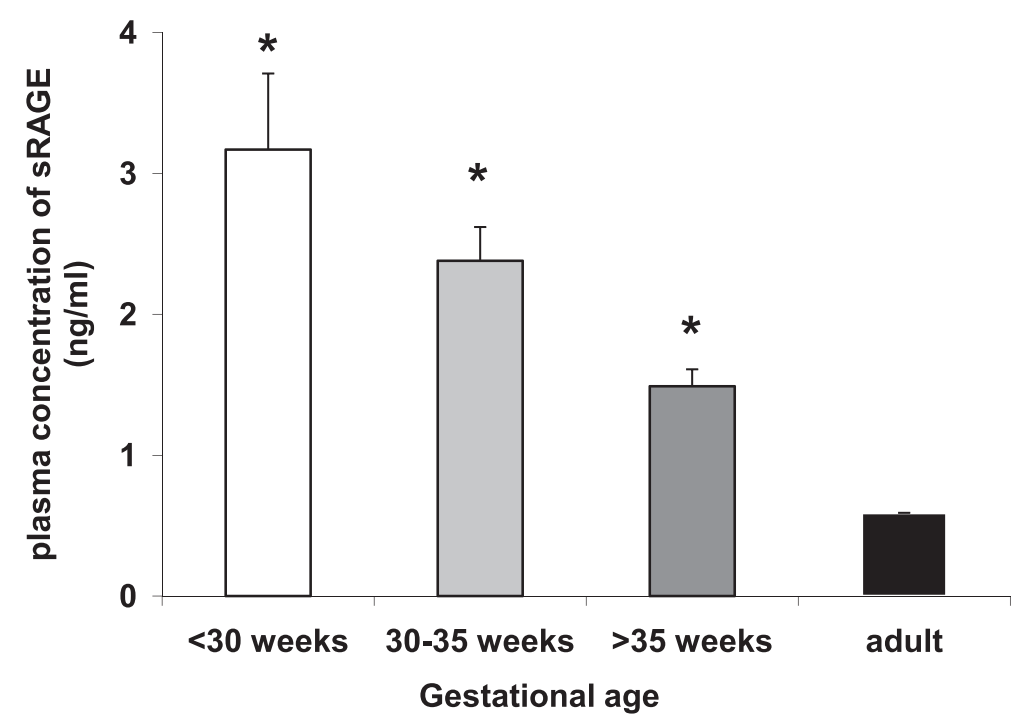

Figure 4 Plasma sRAGE levels in adults and infants during late gestation. The sRAGE plasma concentration of healthy adults was measured and compared to plasma of cord blood of neonates and premature infants (mean + SEM). Significant differences to adult levels are indicated by asterisk $(p<0.05)$.

background adhesion inducing the increase of specific neutrophil adhesion during gestation, we first demonstrated that uncoated control neutrophil adhesion between investigated age groups is not statistically significant (Figure 2A). In addition, we calculated the effective neutrophil adhesion which is the increase of coated neutrophil adhesion over background (= coateduncoated controls, Figure 3). We found that specific, P-selectin-, IL-8-, ICAM-1/RAGE-triggered neutrophil adhesion matures during gestation independently from background adhesion.

Thus, our results indicate that RAGE may be capable to mediate leukocyte adhesion similar to ICAM-1 not only in adults but also during early development. Former experiments in adult mice and humans have shown that RAGE may directly bind to the $\beta_{2}$-integrin Mac-1 and thereby mediate leukocyte adhesion in-vitro and in-vivo [10,11]. In addition, we and others found that RAGE and ICAM-1 collaborate in mediating leukocyte recruitment in a stimulus dependent manner. As addressed later in these studies, RAGE predominantly binds to Mac-1, whereas ICAM-1 is the preferred ligand of the $\beta_{2}$-integrin LFA- $1[10,11]$. Up to date however, it is unclear whether these observations also hold true during fetal development. Moreover, only little is known about signaling properties of RAGE or its interaction with other ligands (i.e. HMBG1, S100) during early life [10,11,26-29].

Since RAGE, in contrast to ICAM-1, is highly expressed during early life [19], our key results of flow chamber experiments might also be of importance for the understanding of cellular immune defense mechanisms in inflammatory conditions during the neonatal period [2-8].

\section{Plasma sRAGE concentration during fetal development}

To test the hypothesis of high fetal RAGE expression in our study population, we measured the concentration of fetal sRAGE in the respective plasma samples of our preterm and term neonates and compared the results to adult sRAGE plasma levels. Indeed, we found that systemic sRAGE concentration is highest in infants born younger than 30 weeks GA and gradually decreases during the course of pregnancy (Figure 4). In term neonates, circulating sRAGE was only about $50 \%$ and during adulthood only $25 \%$ of the values measured in extremely immature infants. Cord blood sRAGE levels at this gestational age were higher than previously reported which might be explained by different techniques of detection [30]. Nevertheless, these findings point towards a distinct role of sRAGE for fetal life and a positive correlation between increased sRAGE and membrane RAGE expression during fetal development [20,21]. With regard to our flow chamber results we now argue that the role of RAGE-dependent leukocyte adhesion may be more prominent during early development than during later life. In combination with an increasing expression and role of ICAM-1 during fetal life [6] RAGE could also be crucial for the tightly regulated balance of fetal immunotolerance and cellular defense.

In a recent study of premature infants with funisitis, sRAGE was found to be decreased in cord blood and in the tracheal fluid [30], and there is increasing evidence that low sRAGE blood levels correlate with poor outcome in infants $[21,45,46]$. Although sRAGE has been additionally described to be associated with many other inflammatory conditions $[28,30,31,47-49]$, it remains 

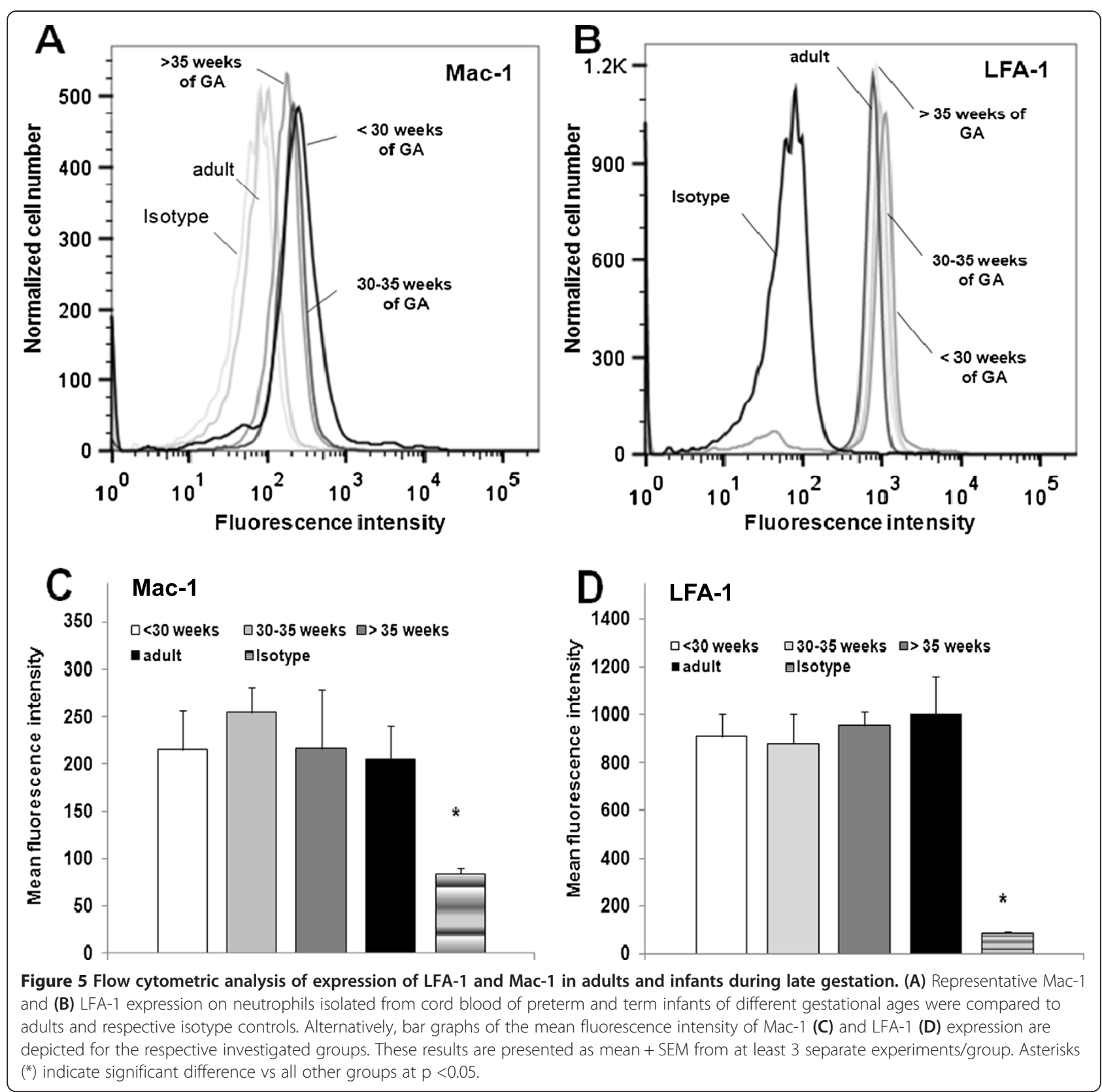

controversial whether a decrease in sRAGE levels is causative or a result of proinflammatory stimulation [25]. Therefore, the exact role of sRAGE for inflammatory conditions particularly during early development still needs to be determined.

\section{LFA-1 and Mac-1 expression during fetal development}

We next investigated the age-dependent expression of the $\beta_{2}$-integrins LFA- 1 and Mac- 1 which are known to be relevant receptors of ICAM-1 and RAGE.

Our flow cytometric investigations of isolated neutrophils revealed a constant LFA-1 and Mac-1 expression during early and late development (Figure 5A-D). In particular, neutrophils form premature and mature infants and adults did not show significant differences in LFA-1 and Mac-1 expression. The tendency of slightly lower Mac-1 expression in some adults (Figure $5 \mathrm{~A}+\mathrm{C}$ ) might be attributed to faster isolation-induced Mac-1-upregulation in neonates (data not shown). These results are consistent with former studies which found similar levels of LFA-1 in preterm infants, neonates and adults, while expression of Mac-1 was reported to gradually increase during pregnancy in some studies [16,50], which might be explained by different experimental conditions.

We suggest, however, that the increase of ICAM-1and RAGE-mediated leukocyte adhesion during early 
development is not primarily caused by altered fetal $\beta_{2}$-integrin expression. Since expression may differ from function, maturation of LFA-1 and Mac-1 activity or avidity could be one explanation of our results. In addition, there are other leukocyte-born binding partners of the adhesion molecules coated in the flow chambers like PSGL-1 and IL-8 receptor [9]. Since PSGL-1 expression is reported to gradually increase with gestational age, while IL-8 receptor expression stays constant during fetal life [6], maturation of PSGL-1 expression can be another explanation of our findings. Moreover, fetal leukocytes could express other or unknown ligands of the coated adhesion molecules when compared to adult leukocytes. In this context one may also ask whether the recently observed homophilic RAGE-RAGE interaction [51] might take place between leukocyte- expressed RAGE and endothelial RAGE in the fetus. However, these questions have not been addressed so far and should be investigated in future studies.

\section{Conclusion}

Our results suggest that impaired neutrophil adhesion of very premature infants only normalizes late during gestation. This study shows for the first time that RAGE controls leukocyte adhesion not only in adults but also in premature and mature infants. The pivotal importance of RAGE is supported by its high expression during fetal life. Thus, new therapeutic approaches for the treatment of inflammatory diseases of preterm infants and neonates could target RAGE, an approach which would most likely be relevant in non-infectious inflammatory diseases. The findings also expand our still incomplete knowledge of the fetal development of the innate immune system.

\section{Additional file}

Additional file 1: Figure S1. Representative May-Gruenwald staining of cell suspension after PMN isolation of cord blood of a term infant. Bar represents $25 \mu \mathrm{m}$. Figure S2. Forward/sideward scatter dot plot of flow cytometric analysis of cell suspension with $10^{5}$ cells before (A) and after (B) isolation of PMNs of adult whole blood (P1 = neutrophils, $\mathrm{P} 2=$ monocytes, P3 = lymphocytes). After isolation (B) 9300 cells (93\%) were detected in the neutrophil gate, $<100$ cells in the monocyte gate $(<1 \%)$ and 300 cells in the lymphocyte gate (3\%) while about 400 cells were outside these gates (4\%). Figure S3. Forward/sideward scatter dot plot of flow cytometric analysis of cell suspension before (A) and after (B) isolation of PMNs of term infants $>35$ weeks of gestational age $(\mathrm{P} 1=$ neutrophils, $\mathrm{P} 2=$ monocytes, $\mathrm{P} 3=$ lymphocytes and erythroid progenitors). After isolation (B) 8800 cells (88\%) were detected in the neutrophil gate, $<100$ cells in the monocyte gate $(<1 \%)$, while 1200 cells $(12 \%)$ were in the lymphocyte gate or outside these gates. Figure S4. Representative screenshot of a recorded flow chamber experiment with leukocytes isolated from a term neonate flowing through a chamber coated with P-selectin, IL-8 and sRAGE after $10 \mathrm{~min}$. Big arrow indicates flow direction. Small arrows indicate adherent leukocytes. White bar represents $30 \mu \mathrm{m}$. Figure S5. Neutrophil adhesion on flow chambers coated with P-selectin $(4 \mu \mathrm{g} / \mathrm{ml}), \mathrm{LL}-8(10 \mu \mathrm{g} / \mathrm{ml})$ and different concentrations of sRAGE is shown as mean + SEM from at least 5 newborns and experiments per concentration. *indicates significant differences $(p<0.05) \mathrm{vs} 0 \mu \mathrm{g} / \mathrm{ml}$ sRAGE.

\section{Abbreviations}

FOV: Field of view; HELLP: Hemolysis, elevated liver enzymes and low platelet count; ICAM-1: Intercellular adhesion molecule-1; LFA-1: Leukocyte functional antigen-1; Mac-1: Macrophage antigen complex 1; PMN: Polymorph-nuclear leukocytes; RAGE: Receptor of advanced glycation endproducts; SRAGE: Soluble RAGE.

\section{Competing interests}

The authors declare that they have no competing interests.

\section{Authors' contributions}

$\mathrm{KB}$ analyzed the data and wrote the manuscript. RT and M-SM performed research and analyzed the data. NB, NK and $\mathrm{HH}$ edited the manuscript. JP contributed analytical tools. DF designed the research and wrote the manuscript. All authors read and approved the final manuscript.

\section{Acknowledgments}

We thank Melitta Weissinger for her excellent technical assistance in performing flow chamber experiments and Prof. Peter Nawroth (Dept of Medicine I \& Clinical Chemistry, University Heidelberg) for providing sRAGE. In addition, we thank Dr Benedikt Fritzsching (Dept Pediatrics, University Heidelberg) for consulting cell isolation.

Received: 29 July 2014 Accepted: 3 November 2014

Published online: 27 November 2014

\section{References}

1. Genzel-Boroviczeny O, MacWilliams S, Von Poblotzki M, Zoppelli L: Mortality and major morbidity in premature infants less than 31 weeks gestational age in the decade after introduction of surfactant. Acta Obst Gynecol Scand 2006, 85:68-73.

2. Fanaroff $A A$, Stoll BJ, Wright LL, Carlo WA, Ehrenkranz RA, Stark AR, Bauer CR, Donovan EF, Korones SB, Laptook AR, Lemons JA, Oh W, Papile LA, Shankaran S, Stevenson DK, Tyson JE, Poole WK, Neonatal Research Network NICHD: Trends in neonatal morbidity and mortality for very low birthweight infants. Am J Obst Gynecol 2007, 196:147 e141-148.

3. Camacho-Gonzalez A, Spearman PW, Stoll BJ: Neonatal infectious diseases: evaluation of neonatal sepsis. Ped Clin North Am 2013, 60:367-389.

4. Boghossian NS, Page GP, Bell EF, Stoll BJ, Murray JC, Cotten CM, Shankaran S, Walsh MC, Laptook AR, Newman NS, Hale EC, McDonald SA, Das A, Higgins RD, Eunice Kennedy Shriver National Institute of Child Health and Human Development Neonatal Research Network: Late-onset sepsis in very low birth weight infants from singleton and multiple-gestation births. J Pediatrics 2013, 162:1120-1124. e1121.

5. Ronellenfitsch S, Weiss C, Frommhold D, Koch L, Mollenhauer J, Poeschl J, Muller H: High DMBT1 concentrations in breast milk correlate with increased risk of infection in preterm and term neonates. BMC Pediatr 2012, 12:157.

6. Nussbaum C, Gloning A, Pruenster M, Frommhold D, Bierschenk S, Genzel-Boroviczeny O, von Andrian UH, Quackenbush E, Sperandio M: Neutrophil and endothelial adhesive function during human fetal ontogeny. J Leukoc Biol 2013, 93:175-184.

7. Sperandio M, Quackenbush EJ, Sushkova N, Altstatter J, Nussbaum C, Schmid S, Pruenster M, Kurz A, Margraf A, Steppner A, Schweiger N, Borsig L, Boros I, Krajewski G-B, Jeschke U, Frommhold D, von Andrian U: Ontogenetic regulation of leukocyte recruitment in mouse yolk sac vessels. Blood 2013, 121:e118-e128.

8. Nussbaum C, Sperandio M: Innate immune cell recruitment in the fetus and neonate. J Repr Immunol 2011, 90:74-81.

9. Ley K, Laudanna C, Cybulsky MI, Nourshargh S: Getting to the site of inflammation: the leukocyte adhesion cascade updated. Nat Rev Immunol 2007, 7:678-689.

10. Frommhold D, Kamphues A, Dannenberg S, Buschmann K, Zablotskaya V, Tschada R, Lange-Sperandio B, Nawroth P, Poeschl J, Bierhaus A, Sperandio M: RAGE and ICAM-1 differentially control leukocyte recruitment during acute inflammation in a stimulus-dependent manner. BMC Immunology 2011, 12:56.

11. Frommhold D, Kamphues A, Hepper I, Pruenster M, Lukić IK, Socher I, Zablotskaya V, Buschmann K, Lange-Sperandio B, Schymeinsky J, Ryschich E, Poeschl J, Kupatt C, Nawroth PP, Moser M, Walzog B, Bierhaus A, Sperandio 
M: RAGE and ICAM-1 cooperate in mediating leukocyte recruitment during acute inflammation in vivo. Blood 2010, 116:841-849.

12. Springer TA: Traffic signals on endothelium for lymphocyte recirculation and leukocyte emigration. Annu Rev Physiol 1995, 57:827-872.

13. Tcharmtchi MH, Smith CW, Mariscalco MM: Neonatal neutrophil interaction with P-selectin: contribution of P-selectin glycoprotein ligand-1 and sialic acid. J Leukoc Biol 2000, 67:73-80.

14. Mariscalco MM, Tcharmtchi MH, Smith CW: P-Selectin support of neonatal neutrophil adherence under flow: contribution of L-selectin, LFA-1, and ligand(s) for P-selectin. Blood 1998, 91:4776-4785.

15. Redl-Wenzl EM, Armbruster C, Edelmann G, Fischl E, Kolacny M, Wechsler-Fördös A, Sporn P: The effects of norepinephrine on hemodynamics and renal function in severe septic shock. Intensive Care Med 1993, 19:151-154.

16. McEvoy LT, Zakem-Cloud H, Tosi MF: Total cell content of CR3 (CD11b/ CD18) and LFA-1 (CD11a/CD18) in neonatal neutrophils: relationship to gestational age. Blood 1996, 87:3929-3933.

17. Rebuck N, Gibson A, Finn A: Neutrophil adhesion molecules in term and premature infants: normal or enhanced leucocyte integrins but defective L-selectin expression and shedding. Clin Exp Immunol 1995, 101:183-189.

18. Lorant DE, Li WH, Tabatabaei N, Garver MK, Albertine KH: P-selectin expression by endothelial cells is decreased in neonatal rats and human premature infants. Blood 1999, 94:600-609.

19. Ott C, Jacobs K, Haucke E, Navarrete Santos A, Grune T, Simm A: Role of advanced glycation end products in cellular signaling. Redox Biol 2014 2:411-429.

20. Lizotte PP, Hanford LE, Enghild JJ, Nozik-Grayck E, Giles BL, Oury TD: Developmental expression of the receptor for advanced glycation end-products (RAGE) and its response to hyperoxia in the neonatal rat lung. BMC Dev Biol 2007, 7:15.

21. Costantine MM, Weiner SJ, Rouse DJ, Hirtz DG, Varner MW, Spong CY, Mercer BM, lams JD, Wapner RJ, Sorokin Y, Thorp JM Jr, Ramin SM, O'Sullivan MJ, Peaceman AM, Simhan HN, Eunice Kennedy Shriver National Institute of Child Health and Human Development (NICHD) Maternal-Fetal Medicine Units Network: Umbilical cord blood biomarkers of neurologic injury and the risk of cerebral palsy or infant death. Int J Dev Neurosc 2011, 29:917-922.

22. Mahajan N, Dhawan V: Receptor for advanced glycation end products (RAGE) in vascular and inflammatory diseases. Int J Cardiol 2013, 168:1788-1794.

23. Bierhaus A, Stern DM, Nawroth PP: RAGE in inflammation: a new therapeutic target? Curr Opin Investig Drugs 2006, 7:985-991.

24. Bierhaus A, Humpert PM, Morcos M, Wendt T, Chavakis T, Arnold B, Stern DM, Nawroth PP: Understanding RAGE, the receptor for advanced glycation end products. J Mol Med (Berl) 2005, 83:876-886.

25. Chavakis T, Bierhaus A, Nawroth PP: RAGE (receptor for advanced glycation end products): a central player in the inflammatory response. Microbes Infect 2004, 6:1219-1225.

26. Chavakis T, Bierhaus A, Al-Fakhri N, Schneider D, Witte S, Linn T, Nagashima M, Morser J, Arnold B, Preissner KT, Nawroth PP: The Pattern Recognition Receptor (RAGE) Is a Counterreceptor for Leukocyte Integrins.J Jxp Med 2003, 198:1507-1515.

27. Schmidt AM, Yan SD, Yan SF, DM S: The biology of the receptor for advanced glycation end products and its ligands. Biochim Biophys Acta 2000, 1498:99-111.

28. Liliensiek B, Weigand MA, Bierhaus A, Nicklas W, Kasper M, Hofer S, Plachky J, Gröne H-J, Kurschus FC, Schmidt AM, Yan SD, Martin E, Schleicher E, Stern DM, Hämmerling G G, Nawroth PP, Arnold B: Receptor for advanced glycation end products (RAGE) regulates sepsis but not the adaptive immune response. J Clin Invest n 2004, 113:1641-1650.

29. Orlova W, Choi EY, Xie C, Chavakis E, Bierhaus A, Ihanus E, Ballantyne CM, Gahmberg CG, Bianchi ME, Nawroth PP, Chavakis T: A novel pathway of HMGB1-mediated inflammatory cell recruitment that requires Mac-1integrin. EMBO J 2007, 26:1129-1139.

30. Thomas W, Seidenspinner S, Kawczynska-Leda N, Wirbelauer J, Szymankiewicz M, Speer CP: Soluble receptor for advanced glycation end products (sRAGE) in tracheobronchial aspirate fluid and cord blood of very low birth weight infants with chorioamnionitis and funisitis. Early Hum Dev 2010, 86:593-598.

31. Buhimschi CS, Baumbusch MA, Dulay AT, Oliver EA, Lee S, Zhao G, Bhandari V, Ehrenkranz RA, Weiner CP, Madri JA, Buhimschi IA: Characterization of RAGE, HMGB1, and S100beta in inflammation-induced preterm birth and fetal tissue injury. Am J Pathol 2009, 175:958-975.
32. Kluin-Nelemans HC, Bolhuis RL, Lowenberg B, Campana D, Sizoo W: Characterization of normal and regenerating bone marrow cells with a panel of monoclonal antibodies. Scand J Haematol 1986, 36:71-78.

33. Nakahata T, Tsuji K, Ishiguro A, Ando O, Norose N, Koike K, Akabane T: Single-cell origin of human mixed hemopoietic colonies expressing various combinations of cell lineages. Blood 1985, 65:1010-1016

34. Eriksson EE, Werr J, Guo Y, Thoren P, Lindbom L: Direct Observations In Vivo on the Role of Endothelial Selectins and alpha(4) Integrin in Cytokine-Induced Leukocyte-Endothelium Interactions in the Mouse Aorta. Circ Res 2000, 86:526-533.

35. Wei X, Runnels JM, Lin CP: Selective uptake of indocyanine green by reticulocytes in circulation. Invest Ophthalmol Vis Sci 2003, 44:4489-4496.

36. Smith ML, Sperandio M, Galkina EV, Ley K: Autoperfused mouse flow chamber reveals synergistic neutrophil accumulation through P-selectin and E-selectin. J Leukoc Biol 2004, 76:985-993.

37. Frommhold D, Ludwig A, Bixel MG, Zarbock A, Babushkina I, Weissinger M, Cauwenberghs S, Ellies LG, Marth JD, Beck-Sickinger AG, Sixt M, LangeSperandio B, Zernecke A, Brandt E, Weber C, Vestweber D, Ley K, Sperandio M: Sialyltransferase ST3Gal-IV controls CXCR2-mediated firm leukocyte arrest during inflammation. J Exp Med 2008, 205:1435-1446.

38. Andreux JP, Renard M, Daffos F, Forestier F: Erythropoietic progenitor cells in human fetal blood. Nouv Rev Franc Hematol 1991, 33:223-226.

39. Forestier F, Daffos F, Catherine N, Renard M, Andreux JP: Developmental hematopoiesis in normal human fetal blood. Blood 1991, 77:2360-2363.

40. Elahi S, Ertelt JM, Kinder JM, Jiang TT, Zhang X, Xin L, Chaturvedi V, Strong BS, Qualls JE, Steinbrecher KA, Kalfa TA, Shaaban AF, Way SS: Immunosuppressive CD71+ erythroid cells compromise neonatal host defence against infection. Nature 2013, 504:158-162.

41. Frenette PS, Mayadas TN, Rayburn H, Hynes RO, Wagner DD: Susceptibility to infection and altered hematopoiesis in mice deficient in both P- and E-selectins. Cell 1996, 84:563-574.

42. Spring FA, Parsons SF: Erythroid cell adhesion molecules. Transfus Med Rev 2000, 14:351-363.

43. Buschmann K, Koch L, Braach N, Mueller H, Frommhold D, Poeschl J, Ruef P: CXCL1-Triggered Interaction of LFA1 and ICAM1 Control Glucose-Induced Leukocyte Recruitment during Inflammation In Vivo. Med Inflamm 2012, 2012:739176.

44. Kaji Y, Usui T, Ishida S, Yamashiro K, Moore TC, Moore J, Yamamoto Y, Yamamoto H, Adamis AP: Inhibition of diabetic leukostasis and blood-retinal barrier breakdown with a soluble form of a receptor for advanced glycation end products. Invest Ophthalmol Vis Sci 2007, 48:858-865.

45. Rogers LK, Graf AE, Bhatia A, Leonhart KL, Oza-Frank R: Associations between maternal and infant morbidities and SRAGE within the first week of life in extremely preterm infants. PLoS One 2013, 8:e82537.

46. Costantine MM, How HY, Coppage K, Maxwell RA, Sibai BM: Does peripartum infection increase the incidence of cerebral palsy in extremely low birthweight infants? Am J Obst Gynecol 2007, 196:e6-e8.

47. Dettoraki A, Gil AP, Spiliotis BE: Association between serum levels of the soluble receptor (sRAGE) for advanced glycation endproducts (AGEs) and their receptor (RAGE) in peripheral blood mononuclear cells of children with type 1 diabetes mellitus.J Ped Endocrinol Metab 2009, 22:895-904

48. Mahajan N, Bahl A, Dhawan V: C-reactive protein (CRP) up-regulates expression of receptor for advanced glycation end products (RAGE) and its inflammatory ligand EN-RAGE in THP-1 cells: inhibitory effects of atorvastatin. Int J Cardiol 2010, 142:273-278.

49. Humpert PM, Djuric Z, Kopf S, Rudofsky G, Morcos M, Nawroth PP, Bierhaus A: Soluble RAGE but not endogenous secretory RAGE is associated with albuminuria in patients with type 2 diabetes. Cardiovasc Diabetol 2007, 6:9.

50. Storm SW, Mariscalco MM, Tosi MF: Postnatal maturation of total cell content and up-regulated surface expression of Mac-1 (CD11b/CD18) in polymorphonuclear leukocytes of human infants. J Leukoc Biol 2008, 84:477-479.

51. Sessa L, Gatti E, Zeni F, Antonelli A, Catucci A, Koch M, Pompilio G, Fritz G, Raucci A, Bianchi ME: The receptor for advanced glycation end-products (RAGE) is only present in mammals, and belongs to a family of cell adhesion molecules (CAMs). PLoS One 2014, 9:e86903.

doi:10.1186/s12865-014-0053-0

Cite this article as: Buschmann et al:: RAGE controls leukocyte adhesion in preterm and term infants. BMC Immunology 2014 15:53. 